\title{
Association of $A B C B 1$ (C3435T) and $A B C C 1$ (G2012T) Polymorphisms with Clinical Response to Atorvastatin in Iranian Patients with Primary Hyperlipidemia
}

\author{
Niusha Behdad ${ }^{1}$, Javad Kojuri ${ }^{2}$, Negar Azarpira ${ }^{3}$, Amir Masoomi $^{1}$ and Soha Namazi ${ }^{* 1}$ \\ ${ }^{1}$ Department of Pharmacotherapy, Faculty of Pharmacy, Shiraz University of Medical Sciences, Shiraz, Iran; \\ ${ }^{2}$ Department of Cardiology, Faculty of Medicine, Shiraz University of Medical Sciences, Shiraz, Iran; \\ ${ }^{3}$ Transplant Research Center, Shiraz University of Medical Sciences, Shiraz, Iran
}

Received 5 December 2015; revised 5 January 2016; accepted 19 January 2016

\begin{abstract}
Background: Atorvastatin is prescribed for the primary and the secondary prevention of coronary artery diseases. A wide variation in inter-individual statin response suggests that genetic differences may contribute to this variation. This study investigated the association of $A B C B 1$ (C3435T) and ABCC1 (G2012T) polymorphisms with clinical response to atorvastatin in Iranian primary hyperlipidemic patients. Methods: Individuals $(n=179)$ with primary hypercholesterolemia were enrolled, and peripheral blood samples were collected. Genotyping of two polymorphisms were performed by amplification refractory mutation system PCR. Results: Following four weeks of treatment, a significant reduction of LDL-C was observed in variant groups (CT+TT) of $A B C B 1(P=0.018)$ and wild-type group (GG) of $A B C C 1$ genes $(P=0.029)$. Logistic regression analysis revealed a significant difference between male and female responses to $10 \mathrm{mg} /$ day atorvastatin $(P=0.004$, odds ratio $=0.2, \mathrm{Cl} 95 \%=0.06-0.6)$. Conclusion: Our finding indicated that these polymorphisms may be attributed to LDL-C serum levels in the primary hypercholesterolemia patients receiving atorvastatin. DOI: 10.18869/acadpub.ibj.21.2.120
\end{abstract}

Keywords: Hypercholesterolemia, Statin, Gene polymorphisms

\section{INTRODUCTION}

$\mathrm{C}$ oronary artery disease $(\mathrm{CAD})$ was responsible for approximately 300,000 deaths in $2010^{[1]}$. It has also been indicated to have a strong association with dyslipidemia ${ }^{[2]}$. The third report of the National Cholesterol Education Program ${ }^{[3]}$ emphasizes the necessity of treatment of lipoprotein abnormalities in patients at high risk for coronary heart disease (CHD). The discovery of 3-hydroxy-3-methylglutarylcoenzyme reductase inhibitors (statins) introduced a highly effective therapeutic approach for the reduction of both morbidity and mortality of patients with established $\mathrm{CHD}^{[4]}$. Serum lipid concentration and individual's responsiveness to statin are influenced by environmental and genetic factors over $50 \%{ }^{[5]}$.
Pharmacogenetic studies have already identified more than 30 genes affecting statin.

P-glycoprotein (P-gp) and multidrug resistance protein $1(A B C C 1)$ play an important role in drug transport through the cell membrane, which may contribute to drug disposition and response ${ }^{[6]}$. P-gp is encoded by a polymorphic gene named multidrug resistance $1(A B C B 1)$, located on chromosome 7. Until now, more than 20 polymorphisms have been recognized; some of which have been associated with altered P-gp expression and activity ${ }^{[6-8]}$.

Several investigations have focused on a synonymous polymorphism in the $A B C B 1$ gene, $C 3435 T$ and reported that this polymorphism is associated with variation in atorvastatin efficacy and safety $^{[9-11]}$. The $C 3435 T$ (rs1045642) is located in the 
exon 26 and has a relationship with differences in total serum cholesterol, LDL-C, and HDL-C in response to atorvastatin in American populations ${ }^{[12]}$. $A B C C 1$ appears to be ubiquitously expressed in many human tissues and transports a wide spectrum of substrates and toxicants ${ }^{[13]}$. A non-synonymous G2012T (rs 45511401) polymorphism, located in exon 16, is common among Caucasian populations ${ }^{[14]}$. Recently, one study has found an association between polymorphisms in $A B C B 1$ and $A B C C 1$ genes and differences in serum LDL-C and HDL-C levels, which indicates the potential role of these polymorphisms in the pharmacogenetics of the atorvastatin ${ }^{[4,15]}$. Regarding these points, this study, for the first time, examined the association of $A B C B 1$ (C3435T) and $A B C C 1$ ( $G 2012 T)$ polymorphisms with para-clinical and clinical responses to atorvastatin in Iranian patients with hyperlipidimia.

\section{MATERIALS AND METHODS}

\section{Study population}

Patients with primary hypercholesterolemia were selected from the outpatients, who were evaluated for the presence of CAD, at the cardiovascular disease clinics affiliated with Shiraz University of medical sciences (Shiraz, Iran) between January 2012 and October 2013. The study protocol was approved by the Ethics Committees of Shiraz University of Medical Sciences (code number 91-01-36-5018). Pregnant women as well as individuals with serum triglycerides above $400 \mathrm{mg} / \mathrm{dl}$ or with thyroid disease $(\mathrm{TSH} \geq 5$ or $\leq 0.4 \mu \mathrm{u} / \mathrm{dl}$ ), renal failure $(\mathrm{SCr} \geq 2 \mathrm{mg} / \mathrm{dl}$ for women, $\mathrm{SCr} \geq 2.5 \mathrm{mg} / \mathrm{dl}$ for men) ${ }^{[16]}$, liver diseases (ALT $\geq 40$ $\mathrm{mg} / \mathrm{dl}$ ), diabetes mellitus (who had two consecutive FBS $\geq 126 \mathrm{mg} / \mathrm{dl}$ ) and individuals treated with oral contraceptives and lipid-lowering drugs were not enrolled in the study ${ }^{[6]}$. All the patients signed an informed consent form. Four weeks before the study, all the subjects visited a dietitian and were instructed to consume a low-cholesterol diet (total daily fat intake 25 to $35 \%$ of total calories, trans fats to less than $7 \%$ of calories $)^{[16]}$. Information on age, gender, body mass index, blood pressure or anti-hypertensive drug history, physical activity (20 minutes walking per day $)^{[16]}$, family history and past medical history of each patient were recorded. Alcoholic and smoker patients were excluded from the study due to the limited numbers. Individuals were categorized into CHD and non-CHD groups according to National Cholesterol Education Program ATP-III guidelines ${ }^{[3]}$. For non-CHD subjects, the risk factor was calculated, and global risk factor assessment was carried out to determine the initial treatment goals. All cases had two or more risk factors and were treated with 10,20 or $40 \mathrm{mg}$ atorvastatin (Sobhan Darou, Tehran, Iran) orally once daily for four weeks. The patients received an appropriate dose of atorvastatin according to their ideal LDL-C goal (patients with CHD, LDL-C $\leq 70 \mathrm{mg} / \mathrm{dl}$ and LDL$\mathrm{C} \leq 130 \mathrm{mg} / \mathrm{dl}$ for non-CHD patients).

\section{Lipid measurement}

One week before and four weeks after atorvastatin administration, peripheral blood samples were collected from the individuals after an overnight fasting $(8-12 \mathrm{~h})^{[16]}$. Total serum cholesterol, HDL-C, LDL-C and triglyceride concentrations were measured. Before and after the administration of atrovastatin, ALT and creatinine kinase were determined to detect the possible adverse drug reactions.

\section{Genotyping}

Genomic DNA was extracted from buffy coat of EDTA-treated peripheral blood samples by the DNP kit (CinnaGen, Tehran, Iran) according to the manufacturer's instruction. Genotyping of the $C 3435 T$ polymorphism on $A B C B 1$ and $G 2012 T$ on $A B C C 1$ was carried out using amplification refractory mutation system PCR method. Briefly, PCR assays were performed with 30-40 ng genomic DNA, $10 \mu$ l Master mix $\left(0.1 \mathrm{U} / \mu \mathrm{l}\right.$ DNA polymerase, $32 \mathrm{mM}\left(\mathrm{NH}_{4}\right)_{2} \mathrm{SO}_{4}$, $5.5 \mathrm{mM} \mathrm{MgCl}_{2}, 130 \mathrm{mM}$ Tris-HCl, pH 8.8, $0.4 \mathrm{mM}$ of each dNTP, $0.02 \%$ Tween-20), $0.6 \mu \mathrm{M} \quad A B C B 1$ reveres primer (5'-GGA GAC CCC CTT ATA AATC-3'), $1 \mu \mathrm{M} A B C B 1$ forward primer (5'-TGG TGT CAC AGG AAG ATA TC-3'), $1 \mu \mathrm{M} A B C C 1$ reveres primer $\left(5^{\prime}-\mathrm{CCA} \mathrm{CCA} \mathrm{CGG} \mathrm{CCA} \mathrm{CCA}\right.$ AAT CAA-3') and $0.7 \mu \mathrm{M} \mathrm{ABCC} 1$ forward primer (5'CTG CCT CAC TTC AAG GGA CAC-3'). The thermal cycle (Techno, Genius, UK) protocol for $A B C B 1$ and $A B C C 1$ consisted of an initial denaturation at $95^{\circ} \mathrm{C}$ for $5 \mathrm{~min}$, followed by 30 and 35 cycles of denaturation at $94^{\circ} \mathrm{C}$ for $25 \mathrm{~s}$ and $40 \mathrm{~s}$, annealing at $59^{\circ} \mathrm{C}$ for $35 \mathrm{~s}$ and $62^{\circ} \mathrm{C}$ for $45 \mathrm{~s}$ and extension at $72^{\circ} \mathrm{C}$ for $25 \mathrm{~s}$ and $40 \mathrm{~s}$. PCR products were analyzed by $2 \%$ agarose gel electrophoresis and stained by SYBR Green dye.

\section{Statistical analysis}

Continuous variables were presented as mean \pm SD. Categorical variables were reported as counts (percentage). To find any potential association between genotypes in candidate genes and demographic phenotypes and response to atorvastatin, we first divided the patients into two different dosage groups, individuals treated with $10 \mathrm{mg}$ atorvastatin per day and those who were treated with 20 or $40 \mathrm{mg}$. To evaluate 
the association between $A B C B 1$ and $A B C C 1$ polymorphisms and serum lipid concentration, individuals carrying the homozygous form of the less common allele were grouped with the heterozygous carriers (variant group), and those carrying the homozygous form of the more common allele were put in the wild-type group. General linear regression model was employed to evaluate the association of C3435T and G2012T genotypes with LDL-C reduction. Logistic regression analysis was carried out to compare the effect of demographic factors and C3435T and G2012T polymorphisms on clinical response to atorvastatin (or achievement of LDL-C to therapeutic goal). The allele frequency of these variants was assessed for deviation from the Hardy-Weinberg equilibrium using Chi-square test. A $P<0.05$ was considered statistically significant. SPSS 17 software (SPSS Inc., Chicago, Illinois) was used for statistical analysis.

\section{RESULTS}

Subjects' characteristics and the frequency distribution of the polymorphisms

Patients $(n=179)$ with primary hypercholesterolemia were enrolled in this study. Based on the laboratory data, the mean $\pm \mathrm{SD}$ of LDL-C, triglyceride, total cholesterol and HDL-C were139.8 $\pm 27.2,163.4 \pm 60.8$, $217.7 \pm 37.9$ and $42.6 \pm 8.6 \mathrm{mg} / \mathrm{dl}$, respectively. As shown in Table 1, environmental factors have similar frequencies between the two dosage groups $(P>0.05)$. The genotype and allele distribution of two polymorphisms are shown in Table 1 . The success rate for obtaining the LDL-C level was $76 \%$.

\section{Effect of $A B C C 1$ and $A B C B 1$ polymorphisms on serum lipid level}

The percentage change in lipid parameters by genotype is shown in Table 2. Multivariate logistic regression analysis showed significant differences between males and females' responses to atorvastatin following four weeks of treatment with $10 \mathrm{mg} /$ day atorvastatin $(P=0.004$, odds ratio $=0.2$, CI 95\% $=0.06$ $0.6)$. The result indicated that women are better responders to the therapy by five-fold. Furthermore, no significant association was detected between the ABCB1 (C3435T) and ABCC1 (G2012T) polymorphisms and clinical response with different dosages of atorvastatin in Iranian hyperlipidemic patients. Linkage disequilibrium between C3435T and G2012T polymorphisms was not observed in our study population $(P=0.56)$.

Table1. Clinical characteristics, genotype and allele frequency of $A B C B 1 / A B C C 1$ in patients with hyperlipidemia

\begin{tabular}{|c|c|c|c|c|}
\hline Characteristics & $\begin{array}{c}\text { Total } \\
(n=179)\end{array}$ & $\begin{array}{c}\text { First group } \\
(n=104)\end{array}$ & $\begin{array}{c}\text { Second group } \\
(n=75)\end{array}$ & $\begin{array}{c}P \\
\text { value }\end{array}$ \\
\hline Age (mean $\pm \mathrm{SD}$, year) & $58.9 \pm 9.4$ & $59.4 \pm 8.7$ & $58.3 \pm 10.1$ & 0.30 \\
\hline $\mathrm{BMI}^{\mathrm{a}}\left(\operatorname{mean} \pm \mathrm{SD}, \mathrm{kg} / \mathrm{m}^{2}\right)$ & $24.0 \pm 3.4$ & $23.7 \pm 3.4$ & $24.4 \pm 3.3$ & 0.96 \\
\hline Female no. $(\%)$ & $66(36.9)$ & $42(40.4)$ & $24(32.0)$ & 0.07 \\
\hline Male no. $(\%)$ & $113(63.1)$ & $62(59.6)$ & $51(68.0)$ & 0.08 \\
\hline Positive family history no.(\%) & $83(46.4)$ & $39(37.5)$ & $44(58.7)$ & 0.24 \\
\hline Positive physical activity ${ }^{\mathrm{b}}$ no. $(\%)$ & $139(77.7)$ & $81(77.8)$ & $58(77.3)$ & 0.95 \\
\hline Positive diet control ${ }^{\mathrm{c}}$ no. $(\%)$ & $145(81.0)$ & $87(83.7)$ & $58(77.3)$ & 0.05 \\
\hline \multicolumn{5}{|l|}{ SNP/genotype } \\
\hline \multicolumn{5}{|l|}{$A B C B 1$ (C3435T) no. $(\%)$} \\
\hline $\mathrm{CC}$ & $5(2.8)$ & $2(1.9)$ & $3(4)$ & 0.07 \\
\hline $\mathrm{CT}+\mathrm{TT}$ & $174(97.2)$ & $102(98.1)$ & $72(96.0)$ & \\
\hline $\mathrm{T}$ allele & $195(54.4)$ & $115(55.3)$ & $80(53.3)$ & 0.8 \\
\hline $\mathrm{C}$ allele & $163(45.6)$ & 93(44.7) & $70(46.7)$ & \\
\hline \multicolumn{5}{|l|}{$A B C C 1$ (G2012T) no.(\%) } \\
\hline GG & $106(59.2)$ & $61(58.7)$ & $45(60.0)$ & 0.8 \\
\hline $\mathrm{GT}+\mathrm{TT}$ & $73(40.8)$ & $43(41.3)$ & $30(40.0)$ & \\
\hline G allele & $262(73.2)$ & $155(74.5)$ & 107(71.3) & 0.08 \\
\hline $\mathrm{T}$ allele & $96(26.8)$ & $53(25.5)$ & $43(28.7)$ & \\
\hline
\end{tabular}

First group received atorvastatin $10 \mathrm{mg} / \mathrm{day}$ and the second group atorvastatin 20 and $40 \mathrm{mg} / \mathrm{day}$. ${ }^{\text {a }}$ Body mass index; ${ }^{\mathrm{b}} 20$-min walking per day; ${ }^{\mathrm{c}}$ Consumption of low fat and calories and high-fiber diet per day 
Table 2. Percentage change in lipid parameters based on C3435T genotype in $A B C B 1$ and G2012T in $A B C C 1$ in each dosage group after four weeks of atorvastatin therapy

\begin{tabular}{|c|c|c|c|c|c|c|}
\hline \multirow{2}{*}{ Variables } & \multicolumn{2}{|c|}{$A B C C 1$} & \multirow{2}{*}{$P$ value } & \multicolumn{2}{|c|}{$A B C B 1$} & \multirow{2}{*}{$P$ value } \\
\hline & GG & GT+TT & & $\mathrm{CC}$ & CT+TT & \\
\hline \multicolumn{7}{|l|}{ First group ${ }^{a}$} \\
\hline LDL-C & $-37 \pm 11$ & $-33 \pm 13$ & 0.02 & $-23 \pm 10$ & $-35 \pm 12$ & 0.01 \\
\hline HDL-C & $6 \pm 2$ & $8 \pm 1$ & 0.11 & $7 \pm 3$ & $8 \pm 3$ & 0.73 \\
\hline Triglyceride & $-17 \pm 10$ & $-18 \pm 12$ & 0.82 & $-10 \pm 6$ & $-8 \pm 8$ & 0.22 \\
\hline Total cholesterol & $-26 \pm 12$ & $-23 \pm 13$ & 0.06 & $-22 \pm 10$ & $-24 \pm 11$ & 0.26 \\
\hline \multicolumn{7}{|l|}{ Second group ${ }^{b}$} \\
\hline LDL-C & $-43 \pm 12$ & $-43 \pm 11$ & 0.81 & $-44 \pm 11$ & $-43 \pm 11$ & 0.63 \\
\hline HDL-C & $6 \pm 4$ & $7 \pm 2$ & 0.26 & $7 \pm 5$ & $7 \pm 4$ & 0.85 \\
\hline Triglyceride & $-17 \pm 8$ & $-20 \pm 4$ & 0.16 & $-20 \pm 10$ & $-18 \pm 9$ & 0.55 \\
\hline Total cholesterol & $-30 \pm 15$ & $-29 \pm 13$ & 0.29 & $-30 \pm 14$ & $-29 \pm 13$ & 0.53 \\
\hline
\end{tabular}

${ }^{a} \mathrm{n}=104$; atorvastatin $10 \mathrm{mg}$ /day); ${ }^{b} \mathrm{n}=75$; atorvastatin 20 and $40 \mathrm{mg}$ /day; LDL-C, low density lipoproteins-cholesterol; HDL-C, high density lipoproteins cholesterol (the mean percentage change $\pm \mathrm{SD}, \mathrm{mg} / \mathrm{dl}$ )

\section{DISCUSSION}

The present investigation showed that the frequencies of the $A B C B 1$ genotype (CC: $2.80 \%$, TT: $11.70 \%$ and CT: $85.50 \%$ ) were not similar to those found in Iranian population in previous studies $(P>0.05)^{[17-19]}$. Azarpira et al. ${ }^{[17]}$ have found $A B C B 1$ wild-type genotype $(3435 C C)$ in $19 \%$ of Iranian renal transplant patients, whereas $51 \%$ and $30 \%$ were heterozygous (3435CT) and homozygous (3435 TT), respectively. The genetic risk variants such as $A P O E$, $P C S K 9, C D K N 2 A$ and $C D K N 2 B$ are associated with conventional risk factors for CAD and very commonly occur in $50 \%$ of the population ${ }^{[20]}$. In this light, we suggest that $A B C B 1$ polymorphism might be considered as a genetic risk factor for CAD development, and it may affect the genotype profile of these patients. However, no data were found regarding $A B C B 1$ genotype distribution in healthy control group to compare with our patient group.

De novo sequencing at $A B C C l$ was performed on 142 healthy individuals from four different populations (Chinese, Malay, Indian and Caucasian) to identify polymorphisms at multidrug resistance protein $1 / A B C C 1^{[21]}$. $\mathrm{T}$ allele frequencies in Caucasians $(2.8 \%)$, Indians $(1.4 \%)$, Chinese $(0 \%)$ and Malay $(0 \%)$ were not similar to those found in our study (T; $25.5 \%)^{[21]}$. Furthermore, G2012T polymorphism was common among Caucasians but it was not detected in Asian populations ${ }^{[21]}$.

In the present study, logistic regression analysis revealed significant differences between males and females' response to atorvastatin regarding the achievement of LDL-C goal after four weeks of treatment with $10 \mathrm{mg} /$ day atorvastatin $(P=0.004$, odds ratio $=0.2$, CI95\% $=0.06-0.6)$. Women in the first group showed better response than men. One study indicated lower mean area under the concentration-time curve and shorter half-life of atorvastatin in women than in $\operatorname{men}^{[22]}$. In a previous study on Japanese women with primary hypercholesterolemia LDL-C level was decreased to a greater extent in women than men after three months of treatment with atorvastatin ${ }^{[23]}$, which was in accordance with our findings. The current study revealed that four weeks of treatment with $10 \mathrm{mg} /$ day atorvastatin significantly reduced LDL-C level in various groups of $A B C B 1$ gene polymorphism $(\mathrm{CT}+\mathrm{TT})$ and wild-type group of $A B C C 1$ gene (GG). The LDL-C reduction demonstrated that the effect of these polymorphisms on atorvastatin efficacy was more clear in low-dose atorvastatin. Taking dose dependency of atorvastatin into consideration ${ }^{[16]}$, we suggest that in higher doses of atorvastatin, the effect of dose is more significant than the polymorphism effects.

In a recent study, Kajinami et al. ${ }^{[10]}$ found no association between $\mathrm{CC}$ genotype of $A B C B I$ and smaller reductions in LDL-C, but larger increases were observed in HDL-C after treatment with atorvastatin (10 mg/day). Furthermore, our study confirmed the investigation by Hoenig et al. ${ }^{[24]}$ on Australian patients treated with $80 \mathrm{mg}$ atorvastatin. The result indicated that the CC genotype at the $C 3435 T$ polymorphism in $A B C B 1$ was associated with reduced atorvastatin efficacy regardless of the cholesterol metabolism following a six-week administration of atorvastatin. In Alzoubi et al. ${ }^{[25]}$ study, both the TT genotype of G2677T (ABCB1) and the TT genotype of the C3435T $(A B C B 1)$ polymorphisms were associated with lower levels of LDL-C after atorvastatin treatment in Jordanians hypercholesterolemic patients. However, the effects of atorvastatin on the levels of total 
cholesterol, triglyceride and HDL-C had no relationship with any of the genotypes in both polymorphisms. In Rebecchi et al. ${ }^{[15]}$ study on Brazilian population, no relationship was found between LDL-C reduction and $A B C C 1$ (G2012T) polymorphism, but $A B C B 1$ and $A B C C 1 \mathrm{mRNA}$ levels were modulated by atorvastatin and $A B C B 1 G 2677 T / A$ polymorphism. Also, $A B C B 1$ baseline expression was related to the differences in the serum LDL-C and ApoB in response to atorvastatin. Unequal group sizes and the risk of selection bias with the groups are the main limitations of this study. A short-term follow-up and the lack of control group for comparison may be considered as other important limitations. However, we concluded that in a low dose of atorvastatin, $A B C B 1$ and $A B C C 1$ polymorphisms may have an effective impact on atorvastatin efficacy in reduction of LDL-C serum level in Iranian patients with primary hypercholesterolemia.

\section{ACKNOWLEDGEMENTS}

This study was financially supported by Shiraz University of Medical Sciences, Shiraz, Iran. The authors wish to thank Hematology Research Center, Kowsar Hospital, and Shahid Faghihi Hospital for their cooperation.

CONFLICT OF INTEREST. None declared.

\section{REFERENCE}

1. Go AS, Mozaffarian D, Roger VL, Benjamin EJ, Berry JD, Blaha MJ, Dai S, Ford ES, Fox CS, Franco S, Fullerton HJ, Gillespie C, Hailpern SM, Heit JA, Howard VJ, Huffman MD, Judd SE, Kissela BM, Kittner SJ, Lackland DT, Lichtman JH, Lisabeth LD, Mackey RH, Magid DJ, Marcus GM, Marelli A, Matchar DB, McGuire DK, Mohler ER 3rd, Moy CS, Mussolino ME, Neumar RW, Nichol G, Pandey DK, Paynter NP, Reeves MJ, Sorlie PD, Stein J, Towfighi A, Turan TN, Virani SS, Wong ND, Woo D, Turner MB. Executive summary: heart disease and stroke statistics-2014 update: a report from the American Heart Association. Circulation 2014; 129(3): 399-410.

2. Adams S, Tsang M, Wright J. Lipid lowering efficacy of atorvastatin. Cochrane database of systematic reviews 2012; 12: CD008226.

3. Expert Panel on Detection, Evaluation, and Treatment of High Blood Cholesterol in Adults. Executive summary of the third report of the National Cholesterol Education Program (NCEP) expert panel on Detection, Evaluation, and Treatment of high blood cholesterol in adults (Adult Treatment Panel III). The journal of the
American medical association 2001; 285(19): 24862497.

4. Superko HR, Momary KM, Li Y. Statins personalized. Medical clinics of North America 2012; 96(1): 123-139.

5. Tosi I, Toledo-Leiva P, Neuwirth C, Naoumova RP, Soutar AK. Genetic defects causing familial hypercholesterolaemia: identification of deletions and duplications in the LDL-receptor gene and summary of all mutations found in patients attending the Hammersmith Hospital Lipid Clinic. Atherosclerosis 2007; 194(1): 102-111.

6. Marzolini C, Paus E, Buclin T, Kim RB. Polymorphisms in human MDR1 (P-glycoprotein): recent advances and clinical relevance. Clinical pharmacology and therapeutics 2004; 75(1): 13-33.

7. Siegmund W, Ludwig K, Giessmann T, Dazert $\mathrm{P}$, Schroeder E, Sperker B, Warzok R, Kroemer HK, Cascorbi I. The effects of the human MDR1 genotype on the expression of duodenal P-glycoprotein and disposition of the probe drug talinolol\&ast. Clinical pharmacology and therapeutics 2002; 72(5): 572-583.

8. Szakacs G, Varadi A, Özvegy-Laczka C, Sarkadi B. The role of $\mathrm{ABC}$ transporters in drug absorption, distribution, metabolism, excretion and toxicity (ADME-Tox). Drug discovery today 2008; 13(9-10): 379-393.

9. Chen CY, Chuang SY, Fang CC, Huang LC, Hsieh I, Pan WH, Yeh HI, Wu CC, Yin WH, Chen JW. Gender difference in statin intervention on blood lipid control among patients with coronary heart disease. International journal of gerontology 2013; 7(2): 116121.

10. Kajinami K, Brousseau ME, Ordovas JM, Schaefer EJ. Polymorphisms in the multidrug resistance-1 (MDR1) gene influence the response to atorvastatin treatment in a gender-specific manner. American journal of cardiology 2004; 93(8): 1046-1050.

11. Shabana MF, Mishriki AA, Issac MSM, Bakhoum SW. Do MDR1 and SLCO1B1 polymorphisms influence the therapeutic response to atorvastatin? A study on a cohort of Egyptian patients with hypercholesterolemia. Molecular diagnosis and therapy 2013; 17(5): 299-309.

12. Thompson JF, Man M, Johnson KJ, Wood LS, Lira ME, Lloyd DB, Banerjee P, Milos PM, Myrand SP, Paulauskis J Milad MA, Sasiela WJ. An association study of 43 SNPs in 16 candidate genes with atorvastatin response. The pharmacogenomics journal 2005; 5(6): 352-358.

13. Leslie EM, Deeley RG, Cole SP. Multidrug resistance proteins: role of P-glycoprotein, MRP1, MRP2, and BCRP (ABCG2) in tissue defense. Toxicology and applied pharmacology 2005; 204(3): 216-237.

14. Yin JY, Huang Q, Yang Y, Zhang JT, Zhong MZ, Zhou $\mathrm{HH}$, Liu ZQ. Characterization and analyses of multidrug resistance-associated protein 1 (MRP1/ABCC1) polymorphisms in Chinese population. Pharmacogenet genomics 2009; 19(3): 206-209.

15. Rebecchi IM, Rodrigues AC, Arazi SS, Genvigir FD, Willrich MA, Hirata MH, Soares SA, Bertolami MC, Faludi AA, Bernik MM Dorea EL, Dagli ML, Avanzo 
JL, Hirata RD. ABCB1 and ABCC1 expression in peripheral mononuclear cells is influenced by gene polymorphisms and atorvastatin treatment. Biochemical pharmacology 2009; 77(1): 66-75.

16. Koda-Kimble MA, Alldredge BK, Corelli RL, Ernst ME. Koda-Kimble and Young's Applied Therapeutics: The Clinical Use of Drugs. Lippincott: Williams \& Wilkins, 2012.

17. Azarpira N, Aghdaie MH, Behzad-Behbahanie A, Geramizadeh B, Behzadi S, Malekhoseinie SA, Raisjalal GH, Rahsaz M, Pourgholami A, Sagheb F. Association between cyclosporine concentration and genetic polymorphisms of CYP3A5 and MDR1 during the early stage after renal transplantation. Experimental and clinical transplantation 2006; 4(1): 416-419.

18. Sabahi Z, Salek R, Heravi R, Mosaffa F, Avanaki Z, Behravan J. Association of gastric cancer incidence with MDR1 gene polymorphism in an ethnic Iranian population. Indian journal of cancer 2010; 47(3): 317321.

19. Taheri M, Mahjoubi F, Omranipour R. Effect of MDR1 polymorphism on multidrug resistance expression in breast cancer patients. Genetics and molecular research 2010; 9(1): 34-40.

20. Roberts R. Genetics of coronary artery disease: an update. Methodist deBakey cardiovascular journal 2014; 10(1): 7-12.
21. Wang Z, Sew PH, Ambrose H, Ryan S, Chong SS, Lee EJ, Lee CG. Nucleotide sequence analyses of the MRP1 gene in four populations suggest negative selection on its coding region. Nucleotide sequence analyses of the MRP1 gene in four populations suggest negative selection on its coding region. BMC genomics 2006; 7: 111.

22. Gibson DM, Bron NJ, Richens A, Hounslow NJ, Sedman AJ, Whitfield LR. Effect of age and gender on pharmacokinetics of atorvastatin in humans. The journal of clinical pharmacology 1996; 36(3): 242-246.

23. Sakabe K, Fukuda N, Fukuda Y, Wakayama K, Nada T, Morishita S, Shinohara H, Tamura Y. Gender differences in short-term effects of atorvastatin on lipid profile, fibrinolytic parameters, and endothelial function. Nutrition, metabolism and cardiovascular diseases 2008; 18(3): 182-188.

24. Hoenig MR, Walker PJ, Gurnsey C, Beadle K, Johnson $\mathrm{L}$. The $\mathrm{C} 3435 \mathrm{~T}$ polymorphism in $\mathrm{ABCB} 1$ influences atorvastatin efficacy and muscle symptoms in a highrisk vascular cohort. Journal of clinical lipidology 2011; 5(2): 91-96.

25. Alzoubi KH, Khabour OF, Al-Azzam SI, Mayyas F, Mhaidat NM. The role of multidrug resistance-1 (MDR1) variants in response to atorvastatin among Jordanians. Cytotechnology 2015; 67(2): 267-274. 